\title{
Producción de hidrógeno a partir de residuos forestales de pino y chopo
}

\author{
Javier Remón Núñez, Lucía García Nieto, Jesús Arauzo Pérez \\ GPT (Grupo de Procesos Termoquímicos) \\ Instituto de Investigación en Ingeniería de Aragón (I3A). \\ Universidad de Zaragoza, Mariano Esquillor s/n, 50018, Zaragoza, Spain. \\ Tel. +34-976762224, e-mail:jrn@unizar.es
}

\section{Resumen}

Los resultados de este trabajo muestran que la producción de $\mathrm{H}_{2}$ a partir de biomasa mediante reformado catalítico de bio-oil se ve afectada por la etapa de pirólisis y por el tipo de biomasa empleada. Ambos factores influyeron en la composición química del bio-oil obtenido en la etapa de pirólisis, lo que se tradujo en diferentes rendimientos a $\mathrm{H}_{2}$ en su posterior reformado.

\section{Introducción}

Los líquidos de pirólisis de biomasa (bio-oil) son una mezcla compleja de un gran número de compuestos obtenidos tras someter a la biomasa a un proceso de pirólisis rápida. Mediante la adición de agua sobre estos líquidos se obtienen su correspondientes fracciones acuosas, consistentes en una mezcla de ácidos carboxílicos, aldehídos, cetonas, alcoholes, azúcares y carbohidratos complejos. En este contexto, en el presente trabajo gracias a la financiación recibida por parte del MICINN (ENE-2010-18985) y a la ayuda FPI (BES-2011-044856) concedida a Javier Remón Núñez, se ha estudiado la producción de $\mathrm{H}_{2}$ a partir de fracciones acuosas de bio-oils obtenidas en la pirólisis de residuos de pino y chopo. Todas las fracciones acuosas se prepararon con una relación $\mathrm{H}_{2} \mathrm{O} / \mathrm{C}=7.6 \mathrm{~mol} / \mathrm{mol}$, utilizando un procedimiento similar al descrito por Sipillä et al. (1998). La etapa de pirólisis tuvo lugar a $490{ }^{\circ} \mathrm{C}$ en un reactor de lecho fluidizado (Chhiti et al., 2011) y un reactor de lecho en surtidor (Makibar et al., 2011). De esta forma, se ha analizado como influye el tipo de biomasa y el tipo de reactor de pirólisis en la composición química de estos líquidos. Posteriormente se relacionó la composición química de las fracciones acuosas con los resultados de producción de $\mathrm{H}_{2}$ utilizando modelos estadísticos empíricos. Los experimentos de reformado se realizaron en un reactor de lecho fijo a $650{ }^{\circ} \mathrm{C}$ con un catalizador $\mathrm{Ni}-\mathrm{Co} / \mathrm{Al}-\mathrm{Mg}$, utilizando un ratio masa de catalizador/caudal de compuestos orgánicos (W/morg $)$ de 4 g de catalizador min/g orgánicos. Más

información sobre la preparación y caracterización del catalizador puede encontrarse en Remón et al. (2013).

\section{Resultados y discusión}

Mediante la caracterización de las fracciones acuosas se encontró que tanto la biomasa de partida como el reactor de pirólisis influyeron en su composición química. Estos resultados son concordantes con los obtenidos por otros autores (Ayalur Chattanathan et al., 2012). En las fracciones acuosas se detectaron y cuantificaron los siguientes compuestos: ácidos (acético, fórmico y propanoico), alcoholes (metanol), aldehídos (hidroxiacetaldehído, acetaldehído y formaldehído), cetonas (1-hidroxy-2propanona), furanos (furfural), azúcares (levoglucosano) y compuestos arómaticos (fenoles, guaiacoles y siringoles). Comparando las fracciones acuosas, se detectaron diferencias estadísticamente significativas con un $95 \%$ de confianza en el contenido en ácido acético, ácido propanoico, formaldehido, furanos y fenoles. En la Tabla 1 se muestra los rendimientos iniciales a $\mathrm{H}_{2}$ y su pérdida porcentual durante dos horas de reacción, obtenidos en el reformado catalítico de las fracciones acuosas empleadas en este trabajo.

Tabla 1. Rendimiento inicial a $\mathbf{H}_{2}$ y pérdida de actividad (media \pm desviación estándar)

\begin{tabular}{lll}
\hline Fracción Acuosa & $\begin{array}{l}\text { Rendimiento } \\
\text { inicial (g/g org) }\end{array}$ & $\begin{array}{l}\mathbf{H}_{2} \text { Pérdida en Rto } \\
\mathbf{H}_{\mathbf{2}} \mathbf{( \% )}\end{array}$ \\
\hline Pino Lecho Fluidizado & $0.182 \pm 0.006^{\mathrm{a}}$ & $81.60 \pm 4.78^{\mathrm{a}}$ \\
Pino Lecho en Surtidor & $0.180 \pm 0.012^{\mathrm{a}}$ & $80.10 \pm 8.03^{\mathrm{a}}$ \\
Chopo Lecho Fluidizado & $0.129 \pm 0.003^{\mathrm{b}}$ & $26.94 \pm 2.74^{\mathrm{b}}$ \\
Chopo Lecho en Surtidor & $0.101 \pm 0.000^{\mathrm{c}}$ & $31.03 \pm 1.29^{\mathrm{b}}$ \\
Equilibrio termodinámico & 0.170 & 0 \\
\hline $\begin{array}{l}\text { a, b y c en cada columna representan grupos homogéneos con un } 95 \% \\
\text { de confianza. }\end{array}$
\end{tabular}

Los resultados de la Tabla 1 muestran que tanto el tipo de biomasa como el reactor de pirólisis tuvieron una influencia significativa en los rendimientos a $\mathrm{H}_{2}$ 
iniciales y en la pérdida de actividad. Se encontró que cuando la biomasa de partida fue serrín de pino, el reactor de pirólisis no tuvo una influencia significativa en el rendimiento a $\mathrm{H}_{2}$ con un $95 \%$ de confianza. Sin embargo, cuando se utilizó serrín de chopo, la fracción acuosa cuyo bio-oil fue procesado en el reactor de lecho fluidizado proporcionó un rendimiento a $\mathrm{H}_{2}$ significativamente mayor que la fracción acuosa cuyo bio-oil había sido obtenido en el reactor de lecho en surtidor. La pérdida en el rendimiento a $\mathrm{H}_{2}$ sólo dependió de la biomasa de partida. Se observó una mayor pérdida en el rendimiento a $\mathrm{H}_{2}$ en el reformado de las fracciones acuosas derivadas de serrín pino que en las derivadas de serrín de chopo.

Relacionando los rendimientos del reformado con la composición química de las fracciones acuosas utilizando el criterio de minimización BIC, se encontró que el diferente contenido en ácido acético, ácido propanoico, formaldehido, furanos y fenoles de las fracciones acuosas fue la causa más plausible (con un $95 \%$ de confianza) del diferente comportamiento de estos líquidos durante su reformado. En las ecuaciones 1 y 2 se muestran los modelos empíricos matemáticos codificados para el rendimiento a $\mathrm{H}_{2}$ y la pérdida de actividad en el rendimiento a $\mathrm{H}_{2}$.

Rto inicial $\mathrm{H}_{2}$ (g/g org) $=0.148-0.022$ [ácido acético] - 0.039 [ácido propanoico] +0.033 [formaldehido] +0.039 [fenoles] (Ec. 1)

Pérdida Rto $\mathrm{H}_{2}(\%)=54.92-29.91 \quad$ [ácido acético](Ec.2)

Analizando ambos modelos matemáticos (Ecuaciones 1 y 2), se obtuvo que cuanto menor es el contenido en ácidos acético y propanoico y mayor es el contenido en formaldehido y fenoles de las fracciones acuosas, mayor es el rendimiento inicial a $\mathrm{H}_{2}$. La pérdida de actividad en el rendimiento a $\mathrm{H}_{2}$ sólo depende del tipo de biomasa, siendo el diferente contenido en ácido acético el responsable de este comportamiento de acuerdo a los modelos estadísticos. Mayores contenidos en ácido ácetico originaron una mayor pérdida del rendimiento a $\mathrm{H}_{2}$.
En el análisis estadístico de los modelos empíricos mediante un diagrama de Pareto, se encontró que el ácido acético fue el compuesto con mayor influencia en rendimiento inicial a $\mathrm{H}_{2}$ (62\%) y en la pérdida del rendimiento a $\mathrm{H}_{2}(100 \%)$.

\section{Conclusiones}

Los resultados de este trabajo muestran que tanto el tipo de biomasa (pino o chopo) como el reactor de pirólisis (lecho fluidizado o en surtidor) tuvieron una influencia significativa en el contenido en ácido acético, ácido propanoico, formaldehido, furanos y fenoles de las fracciones acuosas. A su vez, esta diferencia en la composición química de las fracciones acuosas, originó rendimientos a $\mathrm{H}_{2}$ significativamente diferentes durante la etapa de reformado.

\section{Referencias}

Ayalur Chattanathan, S., Adhikari, S., Abdoulmoumine, N. 2012. A review on current status of hydrogen production from bio-oil. Renewable and Sustainable Energy Reviews, 16(5), 2366-2372.

Chhiti, Y., Salvador, S., Commandré, J.-m., Broust, F.o., Couhert, C. 2011. Wood Bio-Oil Noncatalytic Gasification: Influence of Temperature, Dilution by an Alcohol and Ash Content. Energy \& Fuels, 25(1), 345-351.

Makibar, J., Fernandez-Akarregi, A.R., Alava, I., Cueva, F., Lopez, G., Olazar, M. 2011. Investigations on heat transfer and hydrodynamics under pyrolysis conditions of a pilot-plant draft tube conical spouted bed reactor. Chemical Engineering and Processing: Process Intensification, 50(8), 790-798.

Remón, J., Medrano, J.A., Bimbela, F., García, L., Arauzo, J. 2013. Ni/Al-Mg-O solids modified with $\mathrm{Co}$ or $\mathrm{Cu}$ for the catalytic steam reforming of bio-oil. Applied Catalysis B: Environmental, 132-133, 433-444.

Sipillä, K., Kuoppala, E., Fagernas, L., Oasmaa, A. 1998. Characterization of biomass-based flash pyrolysis oils. Biomass \& Bioenergy, 14(2), 103-113. 